Francisco Giaquinta | frangia.dcv@gmail.com

Facultad de Artes. Universidad Nacional de La Plata. Argentina

Recibido: $23 / 3 / 2020$

Aceptado: $18 / 7 / 2020$

\section{RESUMEN}

En el presente artículo se analizan producciones gráficas realizadas por el diseñador argentino Juan Gatti. La selección de los encargos responde a la presencia de nociones vinculadas con expresiones posmodernas: la generación de estilos híbridos, la recurrencia a referencias del pasado a modo de cita y el uso de la ironía como recurso poético. A través de este artículo se pretende dar relevancia a los aportes que brindan las producciones de Juan Gatti a la disciplina del Diseño en Comunicación Visual.

PALABRAS CLAVE

Diseño posmoderno; afiches; editorial; diseño impreso

\section{ABSTRACT}

This article analyzes the graphic productions by the Argentinian designer Juan Gatti. The selection of the pieces is based on the notions related to postmodern expressions: the creation of hybrid styles, the use of references related to the past and the use of irony as a poetical resource. This article intends to give relevance to the contribution given by Juan Gatti's productions to the Visual Communication Design discipline.

\section{KEYWORDS}

Postmodern design; posters; editorial; print design

\title{
Diseño posmoderno en la obra de Juan Gatti
}

\section{Postmodern Design in the Work of Juan Gatti}



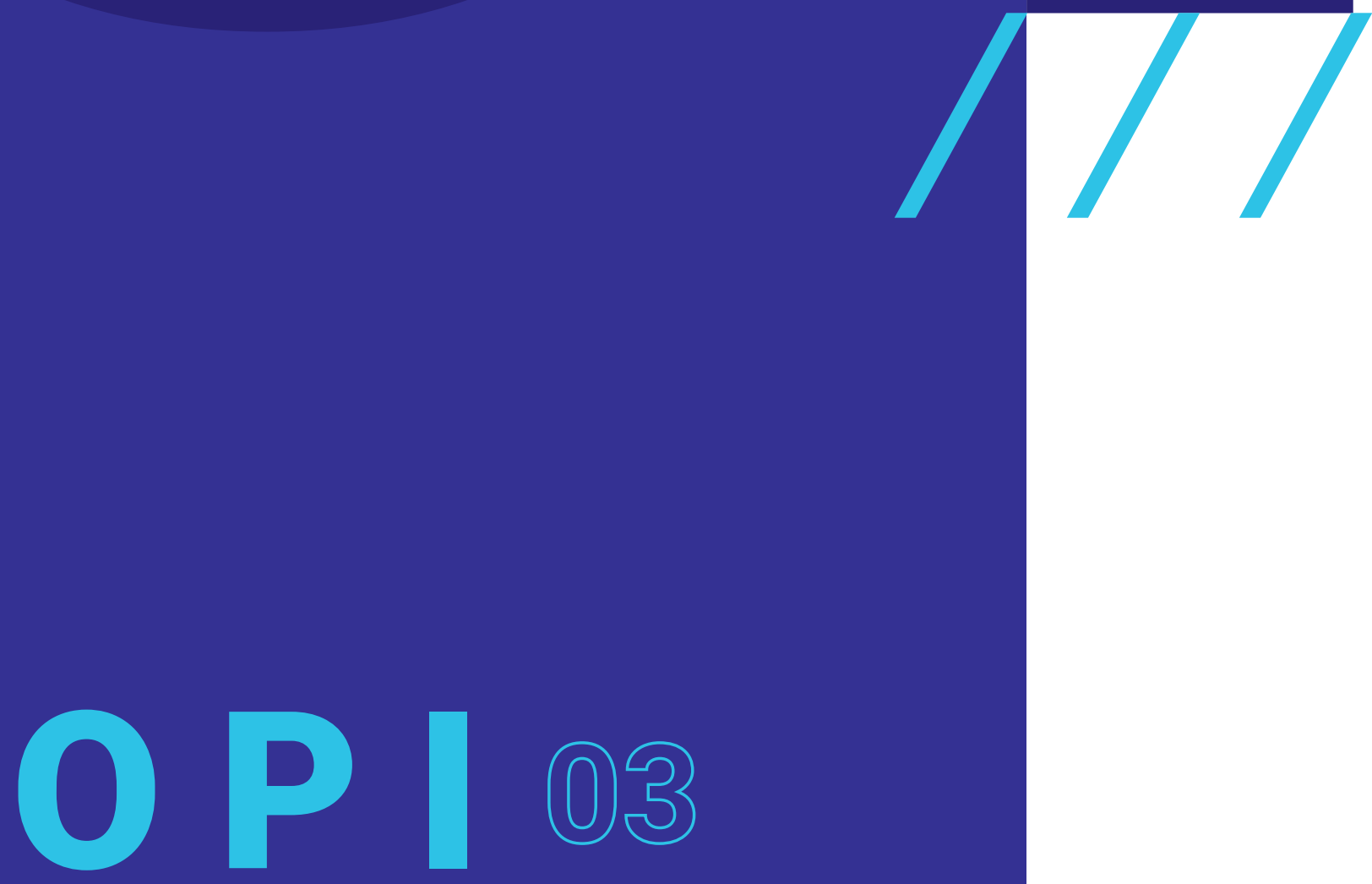

Durante la modernidad se pretendió asumir la historia como un progreso lineal, en el cual el futuro debía superar al presente a través del desarrollo de la ciencia. En el campo del diseño se reflejaron estas nociones a través de propuestas con enfoque racionalista que desearon conseguir una validez universal. Sin embargo, a partir de mediados del siglo Xx comenzaron a registrarse cambios en los paradigmas relacionados al discurso de la época moderna; se manifestó una actitud de descreimiento en el progreso global de la humanidad tras haber ocurrido hechos como el nazismo o el ataque a Hiroshima. Este clima de cambio cultural que se comenzó a percibir recibió el nombre de Posmodernidad. ${ }^{7}$

Cruz Pedroni, Natalia Caride y Eliana Crispino brindados para este artículo.

Desde el campo del diseño la preocupación por alcanzar una propuesta totalmente racionalizada fue puesta en crisis al validarse nuevas posibilidades al momento de producir algún encargo. La comparación que la filósofa Esther Díaz (1999) realiza entre el artista moderno y el posmoderno (aplicable también en este caso a la figura del diseñador) permite comprender la diferencia existente:

El artista moderno apuntaba al futuro y se esforzaba por omitir o negar el pasado. El artista posmoderno, a semejanza del medieval, se fusiona con 
2. En el libro Historia del diseño gráfico (2009), su autor Philip Meggs define el Estilo Tipográfico Internacional como aquel estilo surgido en Suiza, caracterizado por promover una claridad objetiva en piezas gráficas a través de retícula matemática para organizar información

fotografía que transmite de manera fáctica evitando la exageración de la publicidad comercial y el uso de tipografías sin serif por la neutralidad en sus trazos al no poseer ornamentos y la legibilidad que proporcionan 3. Jorge Álvarez fue un productor discográfico y empresario editorial, considerado uno de los principales promotores de la cultura argentina de las décadas de 1960 y 1970. Produjo álbumes de música a través de su propio sello Mandioca los cuales fueron relevantes para la escena de rock argentino, pueden mencionarse los trabajos con Sui Generis, Manal y Luis Alberto Spinetta.

4. El CBGB fue un club emblemático de la música punk y la new wave ubicado en Nueva York. La sigla del nombre se asocia a Country, Bluegrass and Blues, aludiendo a la música que inicialmente tocaban allí los grupos que se presentaban 5. La Movida Madrileña fue un movimiento contracultural surgido en los primeros años de transición de la etapa posfranquista en España. La llegada de las culturas underground provocaron un cambio y una liberación cultura por parte de los jóvenes españoles. Se puede mencionar al local La Rock Ola (1982-1985) como epicentro de este movimiento, lugar donde se reunían jóvenes artistas, fotógrafos músicos, directores de cine, que en su mayoría aún no estaban profesionalizados.

6. La cantante Marta Sánchez señaló en una entrevista para Vanity Fair España que comenzó a sentirse cómoda con su aspecto cuando a Juan Gatti se le ocurrió teñirla de rubio platino para la portada de su segundo disco publicado en 1987 Los caballeros las prefieren rubias. La cantante lo expresó de la siguiente manera: «Hasta entonces había gente que intentaba moldearme de un modo que no me gustaba. Era la época de los new romantics y todo el rato me hacían posar con pelos engominados» (Alonso, 2012, s. p.). el pasado. El pasado puede tener futuro. Ahora se trata de actualizarlo, de leer el pasado desde la ironía y la recreación (p. 27).

Con relación al diseño en comunicación visual, el discurso posmoderno se puede reconocer en proyectos que ya no se preocuparon por el funcionalismo ni la claridad en el mensaje a comunicar tan promulgado por la Escuela Superior de Diseño de Ulm o el Estilo Tipográfico Internacional; $\left.\right|^{2}$ por lo tanto, se comenzaron a experimentar nuevas alternativas en el diseño que permitieron una pluralidad de expresiones, desafiando niveles de legibilidad o retomando el uso de ornamentación (tan negado en la modernidad en busca de formas lo más neutras posibles).

Es relevante definir el marco temporal para poner en valor las producciones gráficas realizadas por Juan Gatti. Comenzaremos por contar que este diseñador argentino empezó sus estudios en Bellas Artes en el año 1968 y para el año 1972, a sus veintidós años, fue nombrado director de arte de una discográfica a cargo de Jorge Álvarez. ${ }^{3}$ Gatti se vinculó con músicos para quienes realizó portadas de discos, algunos de ellos fueron: Moris, Billy Bond, Sui Generis y Pescado Rabioso.

En el año 1978 se mudó a Nueva York, tiempos en que el club CBGB ${ }^{4}$ reunía a referentes musicales del movimiento punk en auge, tales como The Ramones, Sex Pistols, Television y Blondie.

Finalmente, en el año 1980 llegó a Madrid, coincidiendo con el surgimiento de lo que se conoció como la Movida Madrileña. ${ }^{5}$ Es en este espacio cultural donde Gatti residió tras haberse iniciado como director de arte en la discográfica CBS diseñando para grupos de música (Mecano, Tequila, Miguel Bosé, entre otros). Su campo de acción se vinculó a dotar de identidad visual a músicos lo que contemplaba desde el arte de tapa hasta incluso el look. ${ }^{6}$

A continuación, se analizan tres encargos realizados a lo largo de su trayectoria: material de promoción para el cantante Bosé publicado en el año 1982, un afiche diseñado para la película ¡Átame! (1990), del director Pedro Almodóvar, y, por último, una portada de disco para el grupo Fangoria. En cada pieza gráfica se materializan nociones vinculadas al posmodernismo: la mezcla de diversos estilos que producen un híbrido, el hecho de recurrir a referencias del pasado a modo de cita y el uso de la ironía como recurso poético. 


\section{ANÁLISIS DE TARJETA PROMOCIONAL}

El primer análisis se enfoca en una tarjeta de salutación de fin de año realizada para el cantante Bosé [Figura 1]. Para la realización de esta pieza se contó con el fotógrafo Javier Vallhonrat, quien describe el proceso de trabajo junto con Gatti de la siguiente manera:

Intercambios de innumerables citas y referencias visuales de las que se iban destilando esencias, para las que debíamos encontrar refinados correlatos técnicos... planteado el reto conceptual, la sesión era pura magia: la ocasional precariedad de los medios era suplida por ingentes dosis de entusiasmo y exigencia técnica (Gatti en AA.VV., 2012, s. p.).

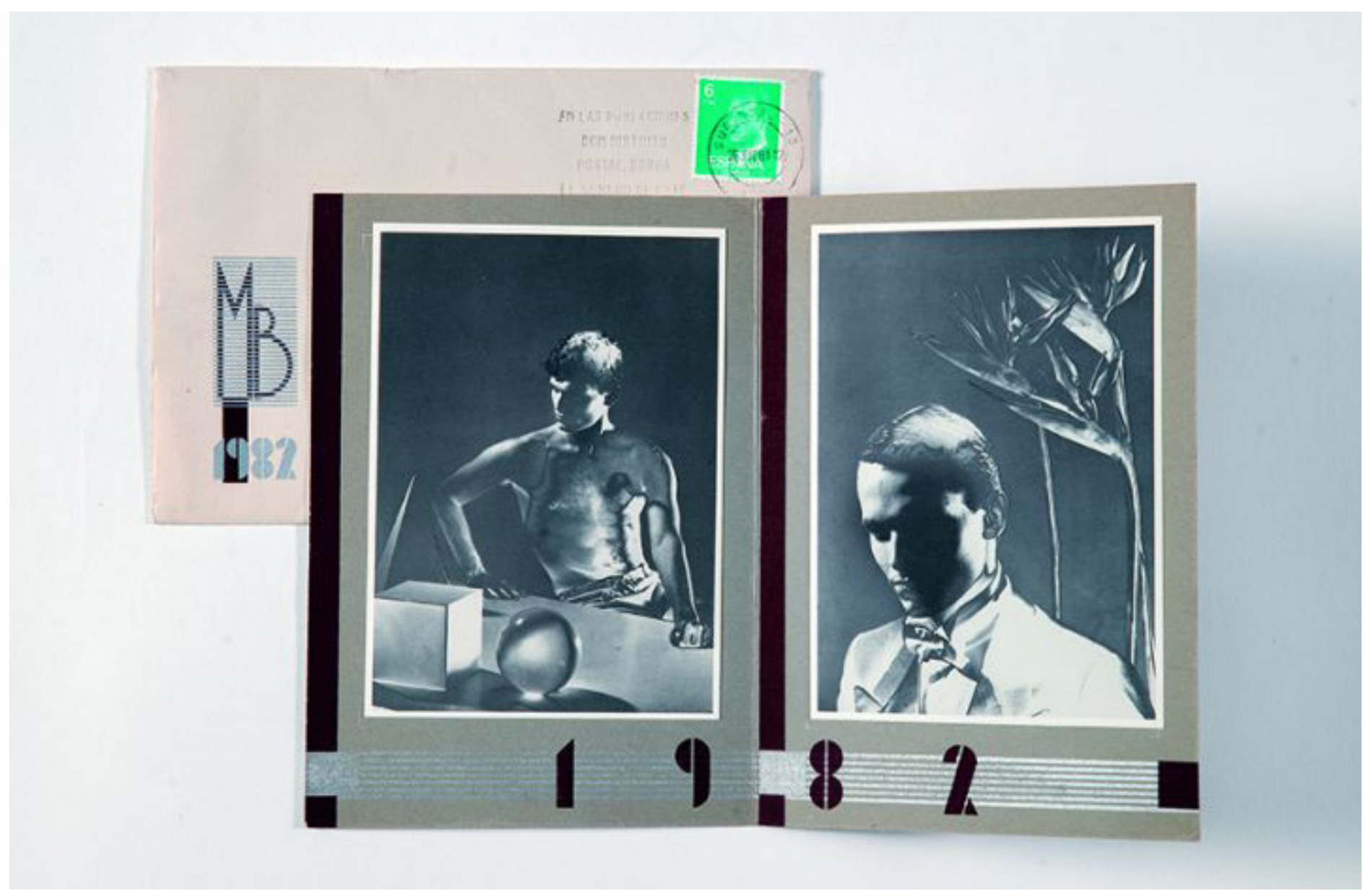

Figura 1. Material promocional para Miguel Bosé (1982), de Juan Gatti y Javier Vallhonrat
Podemos observar cómo se mezclan en esta pieza dos temporalidades estilísticas diferentes. Por un lado, en el tratamiento estilístico de la fotografía se reconoce la obra del artista surrealista Man Ray por el uso del efecto solarizado, el blanco y negro y la presencia de objetos que acompañan al retratado. 


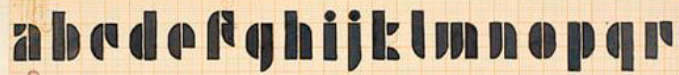 (⿻) 12831367890

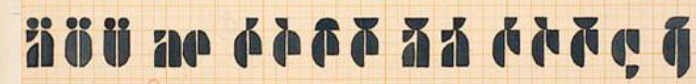

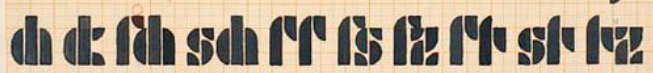 .$: ! ! n{ }^{m 1}=-11$}

Figura 2. Alfabeto (1926), de Josef Albers

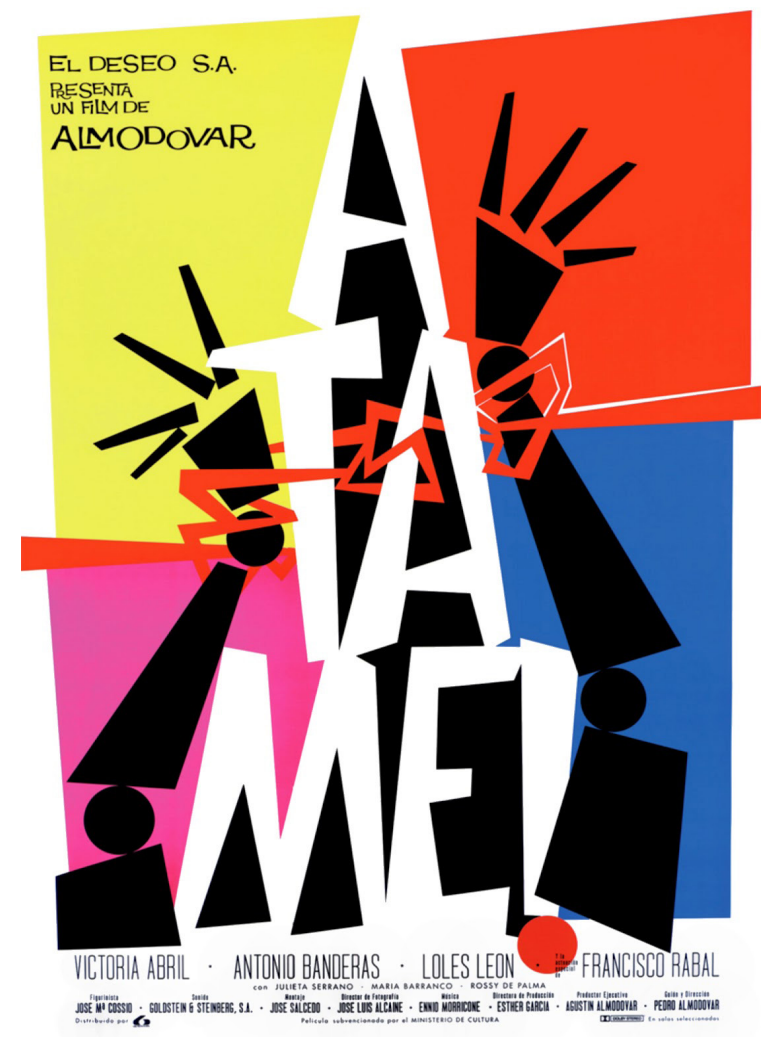

Figura 3. Cartel de Juan Gatti para la película ¡Átame! (1990), de Pedro Almodóvar
Por otro lado, se distingue la utilización de una tipografía correspondiente a un estilo racionalista por la geometrización de los trazos, comparte características muy similares con el alfabeto creado por Josef Albers, representante vinculado a la Bauhaus [Figura 2]. También es válido señalar el uso de una tipografía con rasgos art decó, como puede observarse en el sobre que contenía esta tarjeta en las letras iniciales MB que evocan al nombre del cantante. De este modo, se puede afirmar que Gatti se apropia de estilos del pasado al mezclar sus códigos, lo que da como resultado una pieza ecléctica o híbrida e inscribe estéticas que evocan a diferentes contextos entre sí (y que circulan por un contexto diferente al que referencian).

El autor Andreas Huyssen (en Casullo, 1996) reflexiona acerca de si en este contexto se producen «formas estéticas realmente nuevas o si sólo recicla técnicas y estrategias del mismo modernismo, reinscribiéndolas en un contexto cultural diferente» (p. 270). Gatti recurre a reciclar estilos de la modernidad para revitalizar la imagen de un cantante pop; ofrece, de esta manera, un impacto visual digno de ser objeto de deseo debido a su extrañamiento y rechaza el uso de una propuesta convencional con meros motivos comerciales donde solo se reconozca y admire de forma explícita y directa la figura del cantante. Podemos, entonces, reconocer en el trabajo del diseñador, una necesidad por crear imágenes capaces de generar una afección al ser contempladas, existe la presencia de la búsqueda por conseguir un plus diferencial en sus propuestas visuales.

\section{ANÁLISIS DEL CARTEL PARA ¡ÁTAME!}

En el año 1990 Gatti se encargó del cartel para la película del director de cine Pedro Almodóvar, así como también de los decorados y los diseños que formaban parte de la trama [Figura 3].

Se pueden reconocer en esta dupla estrategias creativas en común, por ejemplo, en el uso de la cita como recurso de forma directa o indirecta a las obras de otros autores. Frédéric Strauss, en su libro Pedro Almodóvar, un cine visceral (1995) detecta cómo el director español se abastece del cine mundial para sus películas, por ejemplo, al comparar una escena de La flor de mi secreto (1995) con Te querré siempre (1954), de Roberto Rossellini: en ambas existe una escena donde un tumulto de personas separa a los personajes principales. Otras veces, la presencia de otras películas construye el relato, lo que en cine se conoce como diégesis: en Kika (1993) el personaje de Ramón está viendo El merodeador (1951), de Joseph Losey, y de este modo descubre quién asesinó a su madre. 
duplicado, sin cansarme jamás, afán sin control, por acumular» (Fangoria, 2009).

Una vez más queda demostrada en esta pieza la puesta en valor que Gatti lleva adelante al recurrir a referencias de manera intencional para permitirse desarrollar un relato conceptual y de manera irónica.

\section{CONCLUSIONES}

Al hacer las comparaciones entre la obra de Gatti y los estilos de los que se apropia no se busca desmerecer su trabajo; muy por el contrario, se pretende valorar su capacidad como diseñador de poseer un amplio conocimiento de referencias a las cuales evocar. A su vez, podemos asociar esta idea con la diversidad de lugares donde este diseñador residió en momentos claves de ebullición cultural que pudieron haber fomentado una amplitud de su conocimiento visual: la consolidación del rock en la Argentina en la década del setenta, el auge del punk en Nueva York a fines de los setenta y la Movida Madrileña en los ochenta en España.

Además, se valora su capacidad para reciclar estéticas y transgredir sus códigos estilísticos que da como resultado imágenes cargadas de un insólito potencial novedoso. Por lo tanto, no se trata solo de citar, sino de reinterpretar y, de esta manera, generar un plus diferencial que desarticula la lógica de la convención y lo estándar.

Estos aportes identificados habilitan pensar la posibilidad de incluir las producciones de Gatti en un lugar relevante dentro de la historia de la disciplina del diseño teniendo en cuenta las nociones condensadas en sus trabajos que permiten relacionarlo con una estética posmoderna.

\section{REFERENCIAS}

AA. VV. (2012). Juan Gatti, PhotoGraphics. Madrid, España: La Fábrica editorial.

Alonso, G. (30 de agosto de 2012). Marta Sánchez: «Me arrepiento de aquella portada de interviú». Vanity Fair España. Recuperado de https://www.revistavanityfair.es/la-revista/articulos/marta-sanchezdesnudo-integral/16864 
Casullo, N. (Comp.). (1996). El debate modernidad posmodernidad. Ciudad Autónoma de Buenos Aires, Argentina: El Cielo por asalto.

Díaz, E. (1999). Posmodernidad. Ciudad Autónoma de Buenos Aires, Argentina: Biblios.

Fangoria. (2009). Más es más. En Absolutamente [CD]. España: Warner Music Spain.

Méjean, J. M. (2007). Pedro Almodóvar. Ciudad Autónoma de Buenos Aires, Argentina: Ma Non Troppo.

Meggs, P. (2009). Historia del diseño gráfico. Barcelona, España: RM.

Strauss, F. (1995). Pedro Almodóvar, un cine visceral. Madrid, España: Ediciones El País. 